6 Irving HC, Parkin GJS. The limitations of oral cholecystography and ultrasonography for the detection of stones in the gall bladder. In: Barbara L, Dowling RH, Hofmann AF, Roda E, eds. Recent advances in bile acid research. New York: Raven Press, 1985:243-6.

De Lacey G, Gajjar B, Twomey B, Levi J, Cox AG. Should cholecystography or ultrasound be the primary investigation for gall bladder disease? Lancet 1984; ; 205-7.

8 Raghavendra BN, Subtramanyam BR, Balthazar EJ, Horii S, Megibow AJ, Hilton S. Sonography of adenomyomatosis of the gallbladder: radiologic-pathologic correlation. Radiology 1983;146:

$747-52$
9 Fowler RC, Reid WA. Ultrasound diagnosis of adenomyomatosis of the gallbladder: ultrasonic and pathological correlation. Clin Radiol 1988;39:402-6.

10 Bellamy PR, Hicks A. Assessment of gallbladder function by ultrasound: implications for dissolution therapy. Clin Radiol 1988:39:511-2.

11 Irving HC, Groves J. Should radiographers perform abdominal ultrasound? A description of a radiographer-based service with the results of 100 patients referred for the investigation of jaundice. Br f Radiol 1985;58:695.

12 Wells PNT. The prudent use of diagnostic ultrasound. Br f Radiol 1986;59:1143-51.

\title{
Life sustaining technology: making the decisions
}

\author{
Learning from America
}

Marking a patient's notes “do not resuscitate," switching off a life support machine, not prescribing antibiotics for life threatening infection: decisions made every day in British hospitals and yet, for all their familiarity, no less difficult for the staff concerned. A recent report from the United States Congress Office of Technology Assessment has looked at how institutional protocols might make taking decisions about life sustaining treatments less fraught. ${ }^{1}$ Protocols for initiating, withholding, or withdrawing treatment from adults with life threatening conditions may be prescriptive or advisory. Treatments may be simple, such as artificial feeding, or complex, such as cardiopulmonary resuscitation. The report discusses the rationale for protocols, considers incentives for and barriers to their introduction, lists the steps needed to introduce them, and offers model examples from various hospitals.

Protocols about making decisions may cover only "do not resuscitate" orders or extend to setting treatment levelspatients in a given category being eligible for all treatments in that and lower categories but not in higher categories. Protocols may define treatment goals, such as to "preserve comfort, hygiene, and dignity but not to prolong life"-in short, supportive care.

The protocols, which are available for scrutiny by staff, patients, and relatives, may articulate the "mission" of the institution (for example, hospice care) and the treatments that will and will not be offered. By ensuring that patients' current or previously expressed wishes are identified and fulfilled they try to preserve patient autonomy and to protect the vulnerable, whose powers are impaired, by identifying and allowing others to act as their advocates. Protocols may include procedures for dealing with conflicts such as those of patient autonomy, the institutional mission, and the moral sentiments of staff, and they may define concepts like "treatment futility" to help staff who might agonise about withholding treatment unjustly.

The report concluded that institutional protocols help to ensure patients' rights, improve communication between patients and staff and among staff members, encourage individual and institutional accountability, and promote ethical treatment. Although the protocols do not carry judicial authority, their existence and implementation are more likely to protect against litigation.

According to the report $57 \%$ of acute care hospitals in the United States had formal "do not resuscitate" policies by 1987 , but only a fifth had protocols for withholding or withdrawing treatments. The prevalence of similar protocols in the United Kingdom is unknown but is almost certainly sparse. Do we need them? After all, more than two thirds of all deaths occur in health facilities, and clinical auditing and consumerism are becoming increasingly important in health care.

Some believe that the trend towards the American style of decision making, more open and more shared, will accelerate in Europe. ${ }^{2}$ Most medical opinion here, however, is against protocols. It maintains that sensitive awareness of the problem and unhurried clinical judgments, sympathy, and mutual trust are enough. ${ }^{3}$ British doctors are thought to be more confident in their relationships with patients than are their transatlantic counterparts ${ }^{4}$ and to be less concerned by litigation or the financial constraints on patients when making clinical decisions about life sustaining technology. ${ }^{5}$ Whether such sentiments always harmonise with the view that authority in medical care should rest with patients or their legal surrogates ${ }^{6}$ is, however, doubtful.

Taking decisions about life sustaining treatment can be stressful for health professionals, whose training may have included little if any clinical ethics and health care law. House officers and nurses are often reported to be confused about what sort of care should be provided, ${ }^{7}$ and doctors' and patients' views of whether or not the patient should be resuscitated may conflict. ${ }^{8}$

In view of our medical conservatism perhaps we need a wider debate about life sustaining protocols. Taking part should be not only actual and potential patients but also the many groups who staff hospitals. One difficulty is the lack of research into the processes and effects of life sustaining treatment and its withdrawal on all concerned. If institutional protocols catch on they should be evaluated even if they seem obviously beneficial. ${ }^{9}$

BRIAN T WILLIAMS

Professor,

Department of Community Medicine,

University of Sheffield Medical School,

Sheffield S10 2RX

1 United States Congress, Office of Technology Assessment. Institutional protocols for decisions about life-sustaining treatments. Washington DC: US Government Printing Office, 1988. (Special report OTA-BA-389.)

Jennett B. Decisions to limit treatment. Lancet 1987;ii:787-8.

3 Bayliss RIS. Thou shalt not strive officiously. Br Med $\mathcal{F} 1982 ; 285: 1373-5$

4 Baskett PJF. The ethics of resuscitation. Br Med $\mathcal{Y} 1986$;293:189-90.

Currie CT. Life sustaining technologies and the elderly. Br Med f 1988;297:3-4.

6 Ruark JE, Raffin TA, Stanford University Medical Center Committee on Ethics. Initiating and withdrawing life support. Principles and practice in adult medicine. $N$ Engl f Med 1988 318:25-30

Evans AL, Brody BA. The do-not-resuscitate order in teaching hospitals. IAMA 1985;253:2236-9.

8 Bedell SE, Delbauco TL. Choices about cardiopulmonary resuscitation in the hospital. When do physicians talk with patients? N Engl f Med 1984;310:1089-93.

9 Lo B. Behind closed doors. Promises and pitfalls of ethics committees. N Engl J Med 1987; 317:46-9. 